\title{
Recomendaciones en cirugía general durante y después de la crisis
}

\author{
Recommendations for Surgery during and after the crisis
}

Juan Roberto Torres Cisneros, ${ }^{*}$ Abilene Cirenia Escamilla Ortiz ${ }^{\ddagger}$

\author{
Palabras clave: \\ SARS-CoV-2, \\ COVID-19, \\ cirugía, equipo \\ protección personal, \\ laparoscopía. \\ Keywords: \\ SARS-CoV-2, \\ COVID-19, \\ surgery, personal \\ protective equipment, \\ laparoscopy.
}

* Presidente de la Asociación Mexicana de Cirugía General. México. \$ Editor de la revista Cirujano General. México.

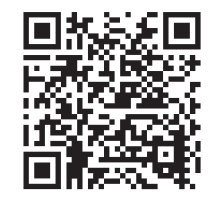

\section{RESUMEN}

El mundo ha cambiado en los últimos meses, ahora la vida gira alrededor de la pandemia causada por SARS-CoV-2, ésta se traduce, sobre todo, en incertidumbre y temor. En la Asociación Mexicana de Cirugía General estamos preocupados por salvaguardar la integridad y salud de nuestros pacientes, al igual que la de los profesionales de la salud y asociados. Lo que antes se manejó como Seguridad del Paciente, ahora incluye también la seguridad para los profesionales de la salud. Los principales sistemas de salud en el mundo se han visto rebasados cuando médicos y enfermeras se contagian o fallecen. Los cirujanos nos vamos a encontrar de lleno en el problema, dado que tenemos que seguir atendiendo la vida de nuestros pacientes, así como la necesidad de realizar intervenciones de urgencias y resolver pacientes oncológicos. Por lo que hacemos las recomendaciones de procedimientos de urgencia, tanto quirúrgicos como endoscópicos, uso del equipo de protección personal, consejos para cirugía laparoscópica tanto para pacientes con COVID-19 o sin éste.

\section{ABSTRACT}

The world has changed in recent months, now life go around the pandemic caused by SARS-CoV-2, which translates all into uncertainty and fear. At the Mexican Association of General Surgery we are concerned with safeguarding the integrity and health of our patients and also the health of professionals and associates. What was previously handled as patient safety now also includes safety for healthcare professionals. The main health systems in the world have been overwhelmed when doctors and nurses become infected or died. Surgeons are going to find ourselves squarely in the problem since we have to continue taking care of the lives of our patients, as well as the need to carry out emergency interventions and solve oncologic pathology. So, we make recommendations for emergency procedures, both surgical and endoscopic, use of personal protective equipment, advice for laparoscopic surgery with or without COVID-19.
$E^{\prime}$ mundo parece haber cambiado en los últimos meses, ya no sólo gira alrededor del Sol, ahora la vida gira en torno a una pandemia viral, COVID-19, causada por el SARS-CoV-2, que continúa evolucionando y generando daños en la salud y economía a nivel global. Esta pandemia se traduce, sobre todo, en incertidumbre y temor, tanto entre la población como entre los médicos.

Seguramente llegará el momento en que regresemos a la vida cotidiana. ¿En cuánto tiempo? Aún no lo sabemos, dependerá de muchas variables, pero definitivamente dejará huella entre nosotros. Nos esperan aún tiempos más difíciles y deberemos estar preparados conociendo a nuestro enemigo viral, conociendo nuestro entorno, con educación para todos y buscando salir de la contingencia de la mejor forma posible.

En la Asociación Mexicana de Cirugía General estamos preocupados por salvaguardar la integridad y salud de nuestros pacientes, al igual que la de los profesionales de la salud y asociados. Lo que antes se manejó como seguridad del paciente, ahora incluye también la seguridad para los profesionales de la salud. Los principales sistemas de salud en el mundo se han visto rebasados cuando médicos y enfermeras se contagian. Los cirujanos nos vamos

Citar como: Torres CJR, Escamilla OAC. Recomendaciones en cirugía general durante y después de la crisis. Cir Gen. 2020; 42(2): 100-108. doi: 10.35366/95368 
a encontrar de lleno en el problema, dado que tenemos que seguir atendiendo la vida de nuestros pacientes, así como la necesidad de realizar intervenciones de urgencias y resolver pacientes oncológicos. Así mismo, vamos a tener que intervenir a pacientes COVID-19 positivos y, llegado el caso y la necesidad, tendremos que bajar a la primera línea a trabajar y ayudar en servicios diferentes a nuestras actividades habituales.

Estamos preocupados por evitar que el cirujano y el personal de salud en general se conviertan en segundas víctimas, como ha sucedido en otros países. Al mismo tiempo, deberemos brindar la mejor atención posible en salud, con la calidad y humanismo que nos caracterizan. Preocupados por cuidar al personal de salud, atendiendo siempre a nuestra vocación de servicio y sin incurrir en omisiones ni irresponsabilidades.

La obligación de los cirujanos, como siempre, será dar atención quirúrgica oportuna y de alta calidad, que logre los mejores resultados para los pacientes. Pero si los equipos quirúrgicos no están adecuadamente protegidos contra la transmisión del virus durante el brote de COVID-19, la capacidad de nuestros sistemas de salud para proporcionar la atención necesaria colapsará, a medida que más y más médicos enfermen o se vean obligados a ponerse en cuarentena.

\section{LAS CONSIDERACIONES DEL COLEGIOAMERICANO DE CIRUJANOS SON LAS SIGUIENTES: ${ }^{1-3}$}

- Educar a los cirujanos y otros trabajadores de la salud sobre la prevención.

- Distancia social e higiene de manos, medidas clave.

- La mayoría de las infecciones virales llegarán al hospital desde la comunidad.

- Hacer pruebas a la mayoría de las personas posibles: profesionales de la salud, cirujanos y pacientes.

- Cancelar todos los procedimientos electivos en pacientes con un pronóstico funcional o vital, que no sea significativamente peor que después de un retraso de dos meses en el tratamiento.

- Cancelar todos los procedimientos y consultas. Implementar soluciones de orientación a distancia.
- Utilizar el comité de ética hospitalario para dar soporte a las decisiones que habrán de tomarse durante las etapas críticas.

- Prohibir la visita de familiares. La tecnología puede ser utilizada para mantenerlos informados y en contacto con sus seres queridos.

- Crear dos áreas o zonas independientes: de COVID negativo y de COVID positivo en la Unidad de Cuidados Intensivos (UCI), quirófanos y áreas de hospitalización.

- El equipo de protección personal (EPP) debe ser utilizado por todo el personal de salud en pacientes positivos y sospechosos que van a cirugía, teniendo en cuenta que en algún momento los insumos faltarán.

- Cuando el virus es muy prevalente en la comunidad, será ideal tener a los pacientes muestreados antes de la cirugía.

- No existen datos suficientes sobre la evolución quirúrgica de pacientes COVID positivos.

- Moverse rápidamente y actuar antes de ver al virus en su hospital. Si no lo hace, será demasiado tarde.

\section{RECOMENDACIONES DE LA ASOCIACIÓN MEXICANA DE CIRUGÍA GENERAL (AMCG) $)^{4-8}$}

La información proporcionada no debe considerarse una guía rígida, y no pretende suplantar el juicio clínico. Tampoco se pretende que la información impida llegar a un consenso con respecto a enfoques institucionales y locales para las pautas de tratamiento. Existe gran incertidumbre en torno a esta pandemia en evolución y una gran cantidad de variabilidad regional. En este ambiente tan variable, la información cambia rápidamente. De tal manera, la AMCG recomienda:

1. Diferir todo procedimiento quirúrgico electivo (cirugías no urgentes): los hospitales y centros quirúrgicos deben evaluar las necesidades médicas de sus pacientes y su capacidad logística y de infraestructura en tiempo real. El riesgo para el paciente debe incluir una evaluación adicional del riesgo real de proceder, contra la demora, incluyendo la posibilidad de que pueda 
ser necesaria una demora de 8 semanas o más para salir de la fase de contagio agudo, aunque no del entorno COVID-19.

Es importante reconocer que la decisión de cancelar o de llevar a cabo un procedimiento quirúrgico debe hacerse en el contexto de estrictas consideraciones médicas, pero también de logísticas locales y a escala nacional.

2. Diferir endoscopía no urgente: puede haber un mayor riesgo de exposición viral durante procedimientos endoscópicos en la vía aérea. Cuando sean necesarios, se debe considerar el uso estricto de EPP para todo el equipo, contra gotas gruesas y aerosoles. Esto incluye, como mínimo, máscaras N95 y caretas.

3. Para la cirugía de urgencia que tenga que efectuarse, recomendamos tener en consideración la posibilidad de contaminación de los instrumentos.

Hay que tomar en cuenta que la dispersión viral en aerosoles se presenta tanto en cirugía abierta como en laparoscópica. Aun cuando puede producir más aerosol en cirugía laparoscópica, en cirugía abierta puede ser más difícil el control mediante aspiración.

La mayor producción de aerosoles se produce durante la intubación y extubación del paciente.

En forma ideal, todo paciente que sea llevado a quirófano deberá tener prueba preoperatoria de COVID-19, si está disponible y es práctico; sobre todo si es accesible en sus hospitales. Dado que puede haber falsos negativos, se sugiere que "todo paciente en el quirófano sea considerado COVID-19 positivo hasta que no se demuestre lo contrario".

Es recomendable hacer tomografía computarizada de abdomen y de tórax a todo aquel que sea llevado a quirófano, en especial si existe dolor abdominal, y que este estudio no tenga más de 24 horas.

\section{Guía adicional para el manejo de cirugías no urgentes durante la pandemia de COVID-19}

4. Consulta externa: deberá ser cancelada toda consulta no urgente, es necesario considerar que nuestros pacientes se verán obligados a romper el aislamiento, desplazarse por la ciudad, Ilegar a los hospitales, estar en contacto con otros, probablemente infectados pero asintomáticos, y que la consulta en sí misma representa un riesgo sanitario para médicos y pacientes, por mucho que se tenga en cuenta las medidas de prevención de la contaminación. Como atención hacia el personal de sus equipos de trabajo, también es recomendable enviar a casa a los no indispensables, reducir la presencia al mínimo y establecer rotaciones. En enfermos con patología neoplásica (oncológica) se valora individualmente los casos, se les atenderá tomando en cuenta todas las medidas de prevención. El médico/cirujano deberá llevar mascarilla. Aumentar la distancia con el paciente y familiar para la entrevista. Recomendar que sólo pase un familiar acompañando al paciente y proceder a la limpieza y desinfección de las zonas de la consulta.

5. Equipo de protección personal (EPP): éste es recomendable para todo procedimiento quirúrgico, y en especial para todas las laparotomías, a menos que se hayan demostrado como COVID-19 negativos (nuevamente considerando que puede haber resultados falsos negativos), incluyendo protección de ojos. Es obligatorio el uso de EPP completo por debajo de la indumentaria quirúrgica para la protección del personal de salud; al ser un procedimiento poco conocido y complicado debe ir precedido por entrenamientos intensivos, evitando así exponer al personal de salud a riesgos innecesarios. La recomendación en este momento es que, incluso, se necesita a dos personas para llevar a cabo la colocación y retiro de este equipo siguiendo una lista de pasos estricta (hoja de verificación).

La búsqueda de una adecuada mascarilla quirúrgica que nos ofrezca la protección adecuada es un tema de relevancia.

\section{Elementos del Equipo de Protección Personal (PPE) (Anexo 1)}

6. Sala de quirófano: deberá permanecer dentro de la sala de operaciones la menor 
cantidad de personal, el mínimo indispensable. Todos deberían usar EPP y protección visual. La intubación y extubación deberá hacerse en el quirófano. Si es necesario y posible, la intubación y la extubación deben realizarse dentro de una sala de presión negativa o neutra. Hay que tener en cuenta que la mayoría de los quirófanos tienen presión positiva y ésta puede hacer que se contamine el resto del quirófano.

Siempre habremos de considerar que los quirófanos están contaminados. https:// www.asahq.org/in-the-spotlight/coronavirus-covid-19-information, https://icmanaesthesiacovid-19.org

Los quirófanos para presuntos, sospechosos o confirmados con COVID-19 positivos deben filtrarse y ventilarse adecuadamente y deben ser diferentes de los utilizados para otros pacientes quirúrgicos emergentes.

Sólo aquellos considerados como personal esencial participarán en el acto quirúrgico (dentro de la sala de operaciones) y, a menos que suceda otra emergencia, no debe haber intercambio de personal de la sala, por ningún motivo. Todos los miembros del personal de quirófano deben usar EPP, según lo recomendado por la Organización Nacional o Internacional, incluida la Organización Mundial de la Salud (OMS) y los Centros de Control de Infecciones (CDC). Se deben utilizar batas y protectores faciales adecuados. Estas medidas deben tomarse en todos los procedimientos quirúrgicos durante la pandemia, independientemente del estado de COVID conocido o sospechado. La colocación y eliminación del EPP debe realizarse de acuerdo con las pautas de los CDC.

Las unidades de electrocirugía deben establecerse en la configuración más baja posible para el efecto deseado. Debe minimizarse el uso de electrocirugía monopolar, disectores ultrasónicos y dispositivos bipolares avanzados, ya que pueden producir aerosolización y dispersión de partículas mediante los vapores. Si está disponible, deben usarse lápices de diatermia monopolar conectados con evacuadores de humo, o tener el aspirador siempre cerca del área electrocoagulada.
Hay que considerar que cuando hacemos cirugía abierta, a los 5 minutos de activación del equipo electroquirúrgico la concentración de partículas de humo en un quirófano puede elevarse de 60 mil a 1 millón de partículas por pie cúbico. Lo que convierte al quirófano en un laboratorio con alta circulación viral; por lo que la ultrafiltración del quirófano es necesaria, especialmente en paciente COVID-19 positivo.

El equipo quirúrgico utilizado durante los procedimientos en pacientes con $\mathrm{CO}$ VID-19 positivo o personas bajo investigación o sospechosos de COVID debe limpiarse separadamente de los otros equipos quirúrgicos.

7. Cirugía laparoscópica: en el principio de la pandemia se consideró la posibilidad de una mayor dispersión de aerosoles durante los procedimientos laparoscópicos y con anestesia general. La producción de aerosoles por bisturí ultrasónico y electroquirúrgico efectivamente puede ser mayor en cirugía laparoscópica, pero también puede ser más fácil de controlar versus la cirugía abierta. Hay que evaluar la relación costo-beneficio de los procedimientos laparoscópicos.

No hay aún suficiente evidencia de que los filtros y medidas improvisadas, como circuitos cerrados de aspiración, sean confiables. En apendicitis se puede considerar el costo-beneficio de la laparoscopia o tomar en cuenta la apendicetomía abierta, si no se tiene la seguridad en el control del neumoperitoneo en una laparoscopia. Lo mismo puede aplicar para otros procedimientos como colecistitis aguda, considerando también que puede ser manejada en forma conservadora durante la época de contingencia.

Aún no hay evidencia clara de los riesgos relativos de la cirugía mínimamente invasiva (laparoscópica) versus el enfoque abierto convencional, específico para COVID-19. Por lo tanto, en todas las sociedades quirúrgicas continuamos monitoreando la evidencia emergente para abordar este problema.

Investigaciones anteriores han demostrado que la laparoscopia y el aire del neumope- 
ritoneo pueden conducir a la producción de aerosoles de virus transmitidos por la sangre. Las recomendaciones para enfermedades altamente transmisibles asociadas con virus están basadas en estudios de hepatitis B y papiloma virus, y hay que considerar que el coronavirus es de trasmisión respiratoria y no se ha demostrado que los aerosoles quirúrgicos contengan al virus.

El SARS-CoV2 está formado por un ARN de una sola cadenade unos 30,000 nucleotidos, tiene un rango de tamaño de 0.06 a 0.14 micrones. El virus se ha encontrado en fosas nasales, saliva, esputo, garganta, sangre, bilis y heces. Las evaluaciones de orina y líquido cefalo raquideo (LCR) han sido negativas. El virus también se ha encontrado dentro de las células que recubren el tracto respiratorio y el tracto gastrointestinal; se sospecha que tiene múltiples modos de transmisión.

Para los procedimientos de mínima invasión, debe considerarse seriamente el uso de dispositivos para filtración del $\mathrm{CO}_{2}$ liberado, contra partículas en aerosol. Los beneficios comprobados de la cirugía de mínima invasión, de estadía reducida y complicaciones, deben considerarse seriamente en estos pacientes, además de la ultrafiltración de la mayoría o de todas las partículas en aerosol. La filtración de partículas en aerosol puede ser más difícil de controlar durante la cirugía abierta.

Se recomienda encarecidamente considerar la posibilidad de contaminación viral para el personal durante la cirugía abierta, laparoscópica o robótica, y que se empleen estrictamente medidas de protección para la seguridad del personal y para mantener una fuerza laboral en funcionamiento.

Los aerosoles pueden dejar el virus prácticamente en todas partes: plástico, metal o cartón, y puede persistir hasta por varios días. Debe considerarse que existe riesgo de contagio por aerolización durante los procedimientos laparoscópicos, por lo que la recomendación es realizar este tipo de cirugías con máscaras faciales con alto porcentaje de filtración de partículas ( $\geq$ N95) y filtros para evacuar el neumoperitoneo.
La filtración puede ser un medio eficaz de protección contra la liberación del virus durante la cirugía mínimamente invasiva (MIS, por sus siglas en inglés) y la endoscopia. Las mascarillas N95 están diseñadas para filtrar 95\% de las partículas de 0.3 micrones o más. Los respiradores purificadores de aire (PAPR), poco disponibles en este momento, pueden ser beneficiosos para la intubación, extubación, broncoscopia, endoscopia y, posiblemente, traqueotomía. Los filtros se utilizan para eliminar el humo y las partículas, incluidos los virus. Los filtros de aire de alta eficiencia (HEPA) tienen una calificación mínima de eficiencia de 99.97\% para eliminar partículas mayores o iguales a 0.3 micrones de diámetro. Los filtros de aire de partículas ultra bajas (ULPA) pueden eliminar un mínimo de 99.999\% de partículas en el aire, con un tamaño mínimo de penetración de partículas de 0.05 micrones. Se considera que los filtros ULPA son capaces de eliminar partículas de 0.1 micrones. La filtración en quirófanos con presión positiva se puede llevar a cabo con los filtros HEPA que se colocan en el techo y en los conductos y proporcionan una filtración adecuada.

\section{Medidas de prevención en la producción de aerosoles}

Hay que considerar la mayor producción de aerosol en la sala de quirófano durante la intubación y extubación, durante la endoscopia de tubo digestivo alto, la cirugía de vías respiratorias alta como orofaringe, la cirugía intestinal y pulmonar.

- Bajar el neumoperitoneo al mínimo indispensable.

- Sellar las válvulas de puertos, con la finalidad de evitar las fugas de aire.

- Electrocauterio y bisturí ultrasónico lo menos posible o nada.

\section{Medidas para evitar la transmisión o contaminación con aerosoles}

- Ultrafiltración del aire con filtros diseñados para el humo quirúrgico, especialmente en neumoperitoneo. 
- Filtro de entrada del $\mathrm{CO}_{2}$ para evitar la contaminación del insuflador cuando la presión intraabdominal es mayor a la del insuflador. Debe haber filtros en la salida del neumoperitoneo para evitar la contaminación de la sala.

El neumoperitoneo debe ser removido a través del filtro, en un sistema cerrado y por completo antes de retirar los trocares.

- Los filtros y medidas improvisadas pueden no ser confiables.

- Mascarillas N95 o mayores.

- Protector de ojos.

En caso de contar con este tipo de equipo de protección, la recomendación es que se realicen procedimientos laparoscópicos utilizando además una presión baja (recomendable 8-10 $\mathrm{mmHg}$ ). Restringiendo el uso de electrocauterio o bisturí ultrasónico, ya que estos instrumentos también generan aerosoles.

Se recomienda no usar drenajes, en especial si se trata de un paciente COVID positivo.

La vía de abordaje quirúrgico deberá ser la de mayor beneficio para el paciente, independientemente de la infección por COVID-19. En cualquier caso, siempre se extremarán las medidas de protección de la vía aérea y mucosas (mascarillas y gafas apropiadas). Asimismo, aunque no existe evidencia al respecto, en caso de disponer de ellos, sería recomendable utilizar filtros de humo en las cánulas de los puertos de laparoscopia.

Medidas prácticas para la laparoscopia

Las incisiones para los puertos deben ser tan pequeñas como sea posible para permitir el paso de los puertos, y sin permitir fugas alrededor de ellos. La presión de insuflación de $\mathrm{CO}_{2}$ debe mantenerse al mínimo y debe utilizarse ultrafiltración (sistema de evacuación de humo o filtración), si está disponible.

Todo el neumoperitoneo debe evacuarse de manera segura a través de un sistema de filtración de aire antes del cierre, extracción del trocar, extracción de la muestra o conversión para abrir.

\section{RECOMENDACIONES PARA CIRUGÍA DE MÍNIMA INVASIÓN: MEJORES PRÁCTICAS}

- Incisiones tan pequeñas como sea posible.

- Baja presión del neumoperitoneo.

- Sellar las válvulas de puertos.

- Filtrar el aire que sale del insuflador.

- Filtrar el aire de neumoperitoneo antes del cierre, extracción del trocar, o conversión.

- Dispositivo de succión/evacuación de aire: ultrafiltración.

- Electrocauterio y bisturí ultrasónico lo menos posible.

- En pacientes con COVID-19 no se recomienda usar drenajes.

\section{CONSEJOS PRÁCTICOS EN LAPAROSCOPIA}

- Usar filtro en insuflador (entrada de $\mathrm{CO}_{2}$ ).

- Uso de filtro entre el frasco aspirador y el aspirador de pared.

- Puerto de cinco o de $10 \mathrm{~mm}$ que se va a usar como ventana para extracción de neblina, conectado a tubo con filtro.

- Cerrar válvula de trocar antes de su introducción a cavidad abdominal.

- Cerrar válvula de trocar antes de conectar o desconectar tubo de $\mathrm{CO}_{2}$.

- Cerrar válvula de trocar cuando se prenda o se apague insuflación de $\mathrm{CO}_{2}$.

- Encender insuflador, luego abrir válvulas de trocar.

- Extraer el $\mathrm{CO}_{2}$ y gas abdominal antes de extraer puertos, sacar piezas, hacer incisiones. Aspirador activado en cualquiera de los trocares de $5 \mathrm{~mm}$ (salida del $\mathrm{CO}_{2}$ ).

En pacientes positivos COVID: todas las anteriores más las siguientes:

- Utilizar medidas de protección que cubran toda piel expuesta: cuello, orejas.

- Realizar vestido y, sobre todo, retiro del

- EPP bajo supervisión, quien va dictando cada acción a realizar.

8. Consentimiento: la discusión del consentimiento con los pacientes debe hacerse informando precisamente el riesgo de 
exposición a COVID-19 y las posibles consecuencias. Todo procedimiento debe contar con consentimiento informado, especificando el riesgo de contagio por SARS-CoV-2 intrahospitalaria y sus consecuencias, las cuales tienen una mortalidad alta durante el postoperatorio, todo esto de acuerdo con la NOM 004/SSA3/2012.

9. Respecto de los trasplantes, CENATRA recomienda suspender temporalmente todos los procedimientos de donación y trasplante. Un caso COVID-19 sospechoso o confirmado no puede ser donador ni receptor.

10. Diferenciar entre infección por COVID-19 y sepsis de origen abdominal: hasta en $10 \%$ de los pacientes puede preceder una sintomatología digestiva como diarrea, náuseas y en pocos casos dolor abdominal. El dolor abdominal que clínicamente se puede confundir con una pancreatitis o sepsis abdominal. A diferencia de la sepsis bacteriana, la infección por COVID-19 no provoca un aumento del recuento de glóbulos blancos, ni una clásica neutrofilia, y es que asocia una linfopenia aproximadamente en $80 \%$ de los pacientes y una plaquetopenia leve en los casos de peor pronóstico. También es frecuente una elevación inespecífica de dímero-D. La procalcitonina se eleva sólo en $5 \%$ en los casos de infección por COVID-19. Sin embargo, la proteína C reactiva (PCR) como en el caso de sepsis, puede elevarse con una relación directa con el pronóstico y gravedad de la enfermedad (Tabla 1).

La anorexia fue el síntoma digestivo más frecuente en adultos, mientras que la diarrea y el vómito fueron los más comunes en

\begin{tabular}{|lc}
\multicolumn{2}{|c|}{ Tabla 1: Manifestaciones } \\
gastrointestinales en COVID-19. \\
\hline Síntomas & Porcentaje \\
\hline Gastrointestinales & 18 \\
Diarrea & 12 \\
Náusea y vómito & 10 \\
Dolor abdominal & 9 \\
\hline
\end{tabular}

adultos y especialmente en niños. El dolor abdominal es más frecuente en pacientes graves.

Los síntomas gastrointestinales parecen ser frecuentes, y se pueden presentar aun sin datos respiratorios. La diarrea y vómito pueden ser causa de consulta y no sospechar rápidamente de COVID-19. El dolor abdominal parece estar relacionado con la disminución de la oxigenación sistémi$\mathrm{ca}$, y puede producir isquemia intestinal, sangrado de tubo digestivo y dolor, íleo y pancreatitis, entre otras alteraciones abdominales.

\section{REFERENCIAS}

1. COVID-19: Guidance for triage of non-emergent surgical procedures. Available in: https://www.facs.org/ about-acs/covid-19/information-for-surgeons/triage.

2. SAGES Recommendations regarding surgical response to COVID-19 crisis. Available in: https://www.sages. org/recommendations-surgical-response-covid-19/.

3. COVID-19-Elective surgical procedure guidance. Available in: http://www.dph.illinois.gov/topicsservices/diseases-and-conditions/diseases-a-zlist/coronavirus/health-care-providers/electiveprocedures-guidance.

4. Information for Healthcare Professionals. Available in: https://www.cdc.gov/coronavirus/2019-nCoV/hcp/ index.html.

5. Strategies for Optimizing the Supply of PPE. Available in: https://www.cdc.gov/coronavirus/2019-ncov/hcp/ ppe-strategy/index.html.

6. Hua ZM, Boni L, Fingerhut A. Minimally invasive surgery and the novel coronavirus outbreak: lessons learned in China and Italy. Ann Surg. 2020; 272: e5-e6.

7. Alp E, Bijl D, Bleichrodt RP, Hansson B, Voss A. Surgical smoke and infection control. J Hosp Infect. 2006; 62: 1-5.

8. COVID 19: Considerations for optimum surgeon protection before, during, and after operation. American College of Surgeons 2020. Available in: https://www.facs.org/-/media/files/covid19/ considerations_optimum_surgeon_protection.ashx.

\section{LECTURAS RECOMENDADAS}

- Audio interview: what clinicians need to know in diagnosing and treating Covid-19. Available in: https:// www.nejm.org/doi/10.1056/NEJMe2004244.

- Covid-19: GP surgeries close for two weeks after staff test positive. Available in: En: https://www.bmj.com/ content/368/bmj.m936.

- Alert: We have 15 critical days to slow the spread of coronavirus. See the latest guidelines from the president and the CDC. Available in: https://www. coronavirus.gov/.

- Recomendaciones generales de actuación y organización básica a servicios de cirugía en 
zonas con alta afectación por la pandemia por COVID-19 (SARS-CoV-2). Disponible en: https:// sites.google.com/view/covid19-porespecialidades/ cirug\%C3\%ADa?authuser $=0$.

- Kwak HD, Kim SH, Seo YS, Song KJ. Detecting hepatitis $B$ virus in surgical smoke emitted during laparoscopic surgery. Occup Environ Med. 2016; 73: 857-863.

- Rubin EJ, Baden LR, Morrissey S. Audio interview: what clinicians need to know in diagnosing and treating COVID-19. N Engl J Med. 2020; 382: e19.

- Gloster HM Jr, Roenigk RK. Risk of acquiring human papilloma-virus from the plume produced by the carbon dioxide laser in the treatment of warts. J Am Acad Dermatol. 1995; 32: 436-441.

- Resources for smoke and gas evacuation during open, laparoscopic, and endoscopic procedures. [Mar 29, 2020 by SAGES Webmaster] Available in: https://www. sages.org/resources-smoke-gas-evacuation-duringopen-laparoscopic-endoscopic-procedures/.

- Aminian A, Safari Saeed, Razeghian A. COVID-19 outbreak and surgical practice: unexpected fatality in perioperative period. Ann Surg. 2020; 272: e27-e29. Available in: https://journals.Iww.com/annalsofsurgery/ Documents/COVID19\%20Outbreak\%20and\%20 Surgical\%20Practice $\% 20-\% 20$ Unexpected $\% 20$ Fatality\%20in\%20Perioperative\%20Period.pdf.

- NOM004/SSA3/2012 Expediente Clínico. Disponible en: https://www.cndh.org.mx/sites/default/files/doc/
Programas/VIH/Leyes\%20y\%20normas\%20y\%20 reglamentos/Norma\%20Oficial\%20Mexicana/NOM004-SSA3-2012.pdf.

- Updated Intercollegiate General Surgery Guidance on COVID-19. Royal College of Surgeons 2020. https:// www.rcseng.ac.uk/coronavirus/joint-guidance-forsurgeons-v2/.

- Steege AL. Secondhand smoke in the operating room? Precautionary practices lacking for surgical smoke. Am J Ind Med. 2016; 59: 1020-1031. Available in: http:// dx.doi.org/10.1002/ajim.22614.

- Cheung KS, Hung IF, Chan PP, Lung KC, Tso E, Liu R, et al. Gastrointestinal manifestations of SARS-CoV-2 infection and virus load in fecal samples from the Hong Kong cohort and systematic review and meta-analysis. Gastroenterology. 2020; 159: 81-95. Available in: https://doi.org/10.1053/j.gastro.2020.03.065.

- Tian Y, Rong L, Nian W, He Y. Review article: gastrointestinal features in COVID-19 and the possibility of faecal transmission. Aliment Pharmacol Ther. 2020; 51: 843-851. Available in: https://doi. org/10.1111/apt.15731.

Correspondencia:

Dr. Juan Roberto Torres Cisneros

E-mail: jrtorcis@hotmail.com

\section{ANEXO 1: ELEMENTOS DEL EQUIPO DE PROTECCIÓN PERSONAL (EPP).}

El EPP será necesario en cualquier procedimiento considerado como "contacto estrecho", lo que incluye intervención quirúrgica, así como otros procedimientos de quirófano (intubación, anestesia regional, canalización de vías, etc.).

\section{EQUIPO NECESARIO:}

1. Bata impermeable.

2. Mascarilla: la mascarilla quirúrgica convencional no ofrece protección si existen aerosoles. Son necesarias mascarillas tipo N95, o FFP2/FFP3 (filtran 96 y 99\%, respectivamente).

3. Gafas: si en el procedimiento se producen aerosoles (asumimos que puede ser así, dependiendo del tipo de cirugía) es fundamental la cobertura ocular de pantalla completa.

4. Pantalla de cobertura facial: no protege de los aerosoles, pero es necesaria cuando existe riesgo de salpicaduras (de sangre, vómito u otros líquidos biológicos).
5. Guantes de nitrilo largos.

6. Es conveniente que todo el personal con el cabello largo se lo recoja completamente en un moño bajo y lo sujete adecuadamente. Se recomienda también afeitarse la barba para favorecer la adecuada fijación y funcionamiento de las mascarillas.

7. Una vez puesto el equipo del EPP, se colocará sobre éste el equipo estéril necesario para la intervención quirúrgica: se realizará el lavado quirúrgico con gel alcohólico sobre los guantes de base y se colocarán la bata y guantes estériles habituales.

\section{INSTRUCCIONES PASO A PASO PARA LA COLOCACIÓN DEL EPP (DONNING)}

Es fundamental que el equipo quirúrgico completo haya realizado entrenamiento previo en colocación y retirada de EPP antes de realizar un procedimiento real. Es muy importante la colaboración de todos los miembros del equipo quirúrgico entre sí. 


\section{PASOS:}

1. Retirar TODOS los objetos personales de los bolsillos del pijama, así como cualquier accesorio (reloj, pendientes, bisutería, etc.) antes de la colocación del EPP.

2. Lavado de manos con solución hidroalcohólica.

3. Se despliega la bata impermeable y se colocan las mangas.

4. A continuación, se coloca la mascarilla. Para su adecuada fijación, lo ideal es sujetarla por la convexidad, aplicarla a la barbilla y pasar las cintas por detrás de la cabeza, se recomienda cruzarlas para una mejor sujeción. Posteriormente, se adapta la pieza metálica sobre el puente de la nariz.

5. Colocación de gafas o pantalla de protección. Las cintas de las gafas deben ajustarse aproximadamente al tamaño de nuestra cabeza antes de colocarlas para evitar la manipulación posterior. En primer lugar, se coloca la gafa sobre la cara, después se pasan las cintas por detrás de la cabeza.

6. Colocarse un par de guantes de nitrilo (talla adecuada) por fuera del traje, cubriendo las mangas del mismo a la altura de los puños.

7. Colocación de gorro quirúrgico (si no se ha colocado otro previamente).

8. Mascarilla: es suficiente con la que se ha colocado ya si el nivel de protección es el adecuado.

9. Lavado (quirúrgico) con gel de alcohol sobre los guantes.

10. Colocación de bata quirúrgica habitual.

11. Colocación de guantes estériles habituales.

\section{INSTRUCCIONES PASO A PASO PARA LA RETIRADA DEL EPP (DOFFING)}

Para la retirada del equipo es fundamental hacerlo de una forma calmada, despacio, evitando movimientos bruscos y con la supervisión de algún compañero entrenado. Lo ideal es que el personal que ha estado en quirófano se retire el EPP de uno en uno. Se debe realizar lo más apartado posible del paciente y cerca de la puerta.

1. Retirarse la bata y guantes quirúrgicos como se hace habitualmente, evitar tocarla, plegarla con la parte externa (donde está la contaminación de sangre, salpicaduras, etc.) hacia dentro, y los guantes vueltos sobre sí mismos. Desechar en el contenedor.

2. Lavado con desinfectante de los guantes de base.

3. Retirar la pantalla protectora, cogiéndola por detrás, agachando la cabeza.

4. Lavado con solución hidroalcohólica.

5. Retirada de los guantes de base. Retirar el primero por la parte externa con un dedo, y el segundo por la parte interna (metiendo el dedo "limpio", entre el guante y el traje). Desechar al cubo con cuidado de no tocarlos, que no toquen nada ni caigan fuera.

6. Lavado de manos con solución hidroalcohólica.

7. Retirada de la bata protectora. En primer lugar, soltar el nudo lateral, a continuación, sin tocar nuestra piel del cuello, traccionar de la bata por la parte superior para despegar los velcros. $\mathrm{Al}$ ir retirando la bata es fundamental no tocar más que la cara interna de la misma, e ir plegándola sobre sí misma para que la parte exterior quede envuelta y cubierta. Se debe levantar con cuidado para evitar que las cintas toquen algo e introducir en el contenedor.

8. Lavado de manos con solución hidroalcohólica.

9. Retirada de las gafas: agachar la cabeza hacia adelante, cerrando los ojos y la boca. Coger las cintas de la parte posterior y retirar con cuidado.

10. Lavado de manos con solución hidroalcohólica.

11. Retirada de la mascarilla: de nuevo, agachando la cabeza y cerrando los ojos y la boca, se sujetan las cintas de la cabeza desde atrás, y se retira hacia delante y hacia abajo. NO se debe tocar la parte delantera de la mascarilla, ya que puede estar contaminada.

12. Lavado de manos con solución hidroalcohólica.

13. Salida del quirófano.

14. Desinfección del calzado, ya sea mediante introducción en desinfectante (pisando filtros) o retirada cuidadosa y desinfección por inmersión.

15. Lavado de manos completo hasta los codos.

16. Es recomendable la ducha tras finalizar el proceso. 